\title{
A temporal geography of encounters
}

Vinicius M. Netto, João Vitor Meirelles, Maíra Pinheiro and Henrique Lorea

\section{OpenEdition}

Journals

\section{Electronic version}

URL: http://journals.openedition.org/cybergeo/28985

DOI: $10.4000 /$ cybergeo.28985

ISSN: $1278-3366$

\section{Publisher}

UMR 8504 Géographie-cités

\section{Electronic reference}

Vinicius M. Netto, João Vitor Meirelles, Maíra Pinheiro and Henrique Lorea, «A temporal geography of encounters », Cybergeo : European Journal of Geography [Online], Space, Society,Territory, document 844, Online since 05 February 2018, connection on 05 February 2018. URL : http:// journals.openedition.org/cybergeo/28985; DOI : 10.4000/cybergeo.28985

This text was automatically generated on 5 February 2018.

(c) CNRS-UMR Géographie-cités 8504 


\title{
A temporal geography of encounters
}

\author{
Vinicius M. Netto, João Vitor Meirelles, Maíra Pinheiro and Henrique \\ Lorea
}

\section{Introduction: linking the social city to the physical city}

\author{
Linking the physical to the social city is the \\ challenge of our times. (Batty, 2017:1) \\ Cities, as Glaeser and Jacobs before him have \\ argued so persuasively, are about 'connections'...
}

(Batty, 2013:30).

1 Among other things, cities are networks of people, institutions and spaces, whose physical organisation allows the exchange of artefacts and information. If linking the social city to the physical city is a major challenge in urban studies (Hillier and Vaughan, 2007; Batty, 2013), the problem of relating social networks to built environments as spatial networks lies at its core. If that is correct, we need to understand the very foundational elements of those relations: the city as "sets of actions, interactions, and transactions... patterns of flows, of networks of relations, pertaining to both physicalmaterial as well as ethereal movements" (Batty, 2013:9). In this paper, we propose to approach these material connections addressing a key condition in the formation of social networks: the opportunities of encounter in time and space.

2 In fact, the city has had the historical role of producing such events. Closer to a more recent trend in urban studies focused on the positioning of agents in space, our approach explores ways in how potential encounters are shaped by the trajectories of bodies in urban space. In other words, we see a great potential in analysing the role of trajectories of different agents in a city as a means to understand patterns of encounter as the circumstances that allow social networks to be formed. Of course this aim involves penetrating a rather elusive fabric of trajectories and encounter. Using ideas from Hunt $\mathrm{e}$ Walker (1974) and Freeman (1978) on segregation as 'restrictions on contact' to 
references to the time-geography of Torsten Hägerstrand (1970), we propose a way of doing that. We aim to:

- explore the role of urban trajectories in the creation of encounter opportunities - and its opposite, in the disjunction of encounters in segregation;

- explore the methodological use of social media locational data to grasp the trajectories of users and infer potential encounters between them;

- apply this framework in an empirical study of trajectories and encounters of people with different income levels in Rio de Janeiro, in order to assess levels of 'real time' segregation and social diversity in the streets;

- finally, we assess how encounters are produced between people with different income levels, and how likely they are, through an analysis of proximity networks based on potential encounters.

3 Let us begin by proposing a concept of sociospatial networks able to represent trajectories and encounters in time and space.

\section{The role of encounters in the formation of social networks}

4 How can cities be part of how we form social networks? A recent view establishes cities as a fluctuating balance of density, mobility and social connectivity (Bettencourt, 2013). Communication and connectivity between people are highly dependent on how encounters are generated as a function of distance, density and mobility. Encounters can be dispersed in the streets or polarized in places of work, leisure and consumption, at bus stops, subway stations, institutional buildings and so on. These factors may have an impact on our interactions, like sparks to a dense web of daily movements from residential locations.

5 Nevertheless, co-presence and encounter may imply different things in different contexts - from open possibilities of interaction to rejection and fear. Following the work of Goffman (1961), Giddens (1984) and Hillier and Hanson (1984), we understand co-presence as bodies positioned within a field where we can perceive the presence of another person (through sight or other senses). In turn, encounter can be defined as being co-present within a distance where interaction becomes possible. Interaction means engaging in communicative exchange by gesture and verbal communication. As the raw material of social life, the importance of encounters can hardly be over-emphasised. However, we do not wish to approach the passage from encounter to interaction, for that would require observations of people in their actual exchanges, which are outside our substantive interest.

6 If movement could leave visible traces, its fabric could reveal opportunities for encounters unfolding in time and space. Mapping this web of movement in the city where encounter may or not happen is one of the aims of this paper. In fact, the idea of mapping trajectories is far from new. The work of Hägerstrand (1970) was the first systematic attempt to capture people's trajectories and spatiotemporal restrictions hanging over actions. Fashionable in the early 1980s, Hägerstrand's approach has gained attention again with a new focus on spatially and temporally integrated approaches (e.g. Netto and Krafta, 1999, 2001; Lee and Kwan, 2011; Kwan, 2013; Park and Kwan, 2017), especially through technologies capable of recording the movement of people and identify patterns 
of spatiotemporal appropriation (e.g. Gonzales et al, 2008). We wish to add new layers to this idea, and evaluate how trajectories shape opportunities of encounter. These trajectories are of course elusive features of our presence in space. If we could capture at least traces of them, we could produce a picture of how people and perhaps different social groups materialize their potentials for interaction.

For capturing the generative role of encounters, we would like to explore an alternative definition of 'social network'. We consciously opt to not use the concept as an arrangement of agents as in Social Network Analysis (SNA). ${ }^{1}$ The SNA tradition uses graph theory and focuses on the microstructural analysis of networks varying from epidemics and power relations to small-worlds - frequently in a space without physical and temporal dimensions, an abstract space of pure topology. We prefer to define social network as an open and potential set of contacts changing over time - one able to account the social positions of agents and the circumstances where contact may occur.

Graphically, we do not represent agents by vertices and relationships by links. Instead, we invert this representation, seeing agents as 'lifelines' (like Hägerstrand), adding the important factor of time, allowing us to retain a dynamic property of social systems. The possibility of agents encountering each other is represented by the intersections of the lifelines. Encounters are vertices, and agents' lifelines the links between them. This nonstandard representation is favoured by a principle of homology in which lifelines correspond to urban trajectories, and circumstances of encounter correspond to converging positions in time and space (figure 1). Places of converging trajectories are places of potential encounter and connection. Of course this model seeks to add the temporal and spatial dimensions as inherent dimensions of social networking, and render the materiality of encounter more intuitive. In short, it is intended to account for the potential of encounter as a key factor in social network formation.

Figure 1: Principles of homology and the diagrammatic translation (centre) between paths in time (left), and paths in space-time (right).
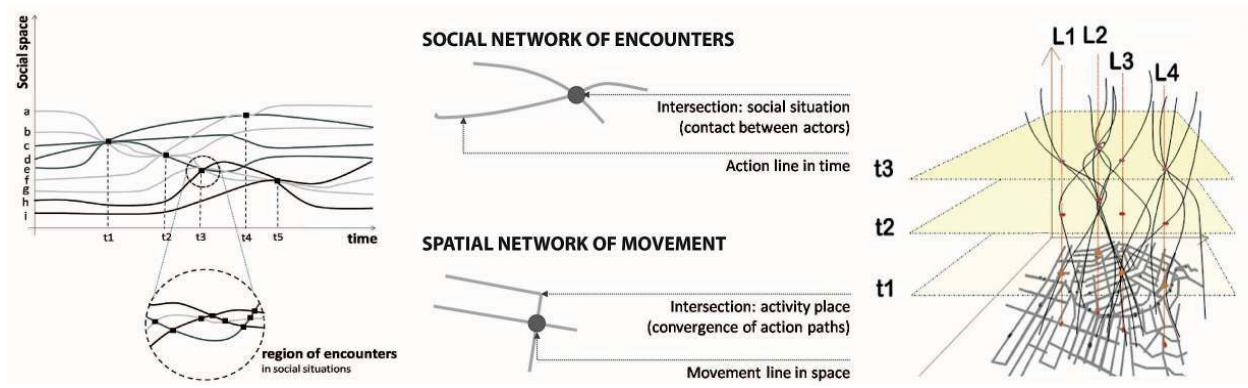

Once we map agents' lifelines in space-time, as trajectories between positions or activities, we leave a purely 'social' representation of networks behind. We are looking at social and spatiotemporal networks. We suggest that this approach can be especially useful to detect potentials of encounter which might either lead to greater interaction between people or to a systematic lack of contact - a subtle and pervasive form of 'real time' segregation in urban life. Let us see how this could be the case. 


\section{Trajectories and potential contact between socially different groups}

10 An interesting view of the potential impact of encounters on social networks is found in Freeman (1978: 413): "All restrictions on interaction, whether they involve physical space or not, are forms of segregation - in social space." Freeman's concept suggests that the absence of encounters between people can engender a subtle but effective form of segregation, especially between socially different people. This focus on segregation based on people rather than places is a recent trend in segregation studies (Netto and Krafta, 1999, 2001; Schnell and Yoav, 2001, 2005; Lee and Kwan, 2011; Kwan, 2013; Selim, 2015; Netto et al 2015; Wissink et al, 2016; Park and Kwan, 2017; Netto, 2017). This offers a whole new perspective on the delicate fabric of encounters keeping local social systems together. Conditions of encounter and interaction are shaped by social difference, including among other things lifestyles influenced by behavioural possibilities and interests afforded by different levels of income. Social differences determine compatibilities and incompatibilities, proximities and distances and shape the probability of people constituting themselves as practical groups (Bourdieu, 1985). Inversely, differences may hinder the approximation between agents. Characteristics of agents play an active role in the generation of situations of encounter.

11 So what is our chance of meeting someone from a different social group in a city? Mapping movement can help us understand the emergence of situations and clusters of encounter between social groups. For instance, certain areas in a city (say, a busy street, the centre business district or a local centrality), well served by transport, can attract people with different income levels. Activity places can increase the potential for encounters between those who share similar interests and mobilities. Income plays a role in this. People with smaller budgets face more restrictions in mobility. ${ }^{2}$ In turn, limitations in mobility enhance localism, the dependency on proximity to produce stable social relationships (see Fischer and Shavit, 1995; Lee et al., 2005). In these cases, people would tend to use places in the neighbourhood to create and maintain relationships. Other empirical studies showed that residential segregation, higher levels of homophily (similarity within social networks) and different degrees of connectivity in personal networks relate to differences in income (Marques, 2012).

In turn, similarities in patterns of mobility and appropriation of space (the spaces we are likely to use or pass by) seem to increase the density of encounters between socially similar people (Netto et al, 2015). If this were the case in different cities and contexts, it could also imply reductions in possibilities of contact between the socially different. Income, residential location and mobility seem associated in a circle that leads to systematic increases or decreases in the potential to create, maintain and expand personal networks. But how so? How and where does the potential of encounter between the socially different materialize?

In order to answer this question, we need to examine the trajectories of socially different people and where they overlap. These would be the places of encounters opportunities. Even though we do not usually think about it, our daily trajectories constitute the backbone of our encounters and social life. On the one hand, poor and rich may live far from each other, but they move around and may even share spaces of co-presence. On the other hand, distance between locations in a city, associated with differences in mobility, 
income and lifestyle could bring inequalities in the capacity to access certain places or areas, and participate in social situations. Differences and incompatibilities in patterns of movement are forms of disjunction of encounters - a way of disrupting the possibility of social contact that otherwise could emerge (Netto, 2017). The disjunction of encounters may be especially active among socially different people. Simply put, there would be a greater chance of encountering and networking with those who share similar income levels.

hypothesis is that the probability of encounters between large-scale groups includes but goes beyond residential location and spatial segregation. It would be shaped by income, by the distribution of activities such as homes and work along accessibility channels, and by different trajectories. These ideas begin to portray the elusive fabric of encounters in a city, a fabric embedded with subtle forms of 'real time segregation' expressed in daily trajectories. But how can we reach a precise 'geography of encounters' in time involving large numbers of people?

\section{The methodological use of Twitter locational data}

15 The idea of visualizing the tremendously complex flows of people and their activities in a city used to seem nearly impossible. Recently this started to change with the introduction of digital networks and devices able to record the movement of large numbers of people. Many works have used social media locational data in order to extract information of human patterns of movement. For instance, Lee et al (2011) examine how the use of mobile communication channels of information affects just-in-time choices in consumption travelling behaviour. Li et al (2011), Ribeiro et el (2012) and Zielinski and Middleton (2013) developed forms to infer indirect locations from Twitter geotag and timestamp, whereas Veloso and Ferraz (2011) and Takhteyev et al (2012) derived spatially reliable information through regression models correlating tweet frequencies with real world events. Sakaki et al (2010) filtered georeferenced tweets, whereas Boettcher and Lee (2012) applied density-based spatial clustering.

In the spirit of these works, we conducted an empirical study in the city of Rio de Janeiro using Twitter metadata. Twitter offers particularly attractive possibilities in this sense, as it makes its metadata bank public through a principle of anonymity. The set of variables provided by Twitter API includes user IDs along with a spatiotemporal signal, the timestamp and geographic coordinates for each tweet posted by users who opted for having the GPS location in their mobile phones turned on. This offers the possibility of inferring characteristics of spatial behaviour at the individual level, involving potentially large samples. Naturally, risks of generalizing behaviour from self-selecting users to larger populations from which they are drawn must be carefully taken into account (Longley et al, 2015). Our study is intended as a proxy to the actual scenario of trajectories of socially differentiated agents. We approached this problem through a number of methodological steps.

- We collected metadata from tweets with spatiotemporal positions posted in Rio through the official Twitter streaming API between November $12^{\text {th }}$ in 2016 (0:07:13 am) and $14^{\text {th }}(2: 36: 45)$, during a period of 56 hours of continuous and stable recording, generating a database of 20,192 users and 333,407 tweets. Due to computational limits, especially considering procedures such as generating shortest paths between tweet locations, we opted for working with this sample. We also managed to test this sample against a 241 hours database, with 
70,403 users and 2,252,348 tweets collected along 18 days, and found a Pearson linear correlation of 0.98 ( $\mathrm{p}$-value 2.2e-16) between the datasets regarding the spatial distribution of tweets according to census blocks, suggesting that the initial sample accurately reflects the larger number of observations. Census blocks were adopted as the most finely grained, statistically significant data source regarding income available in the Brazilian context (step 1).

- Step 2 focused on recognizing useful Twitter users. Firstly, we attempted to differentiate human users from automated users (Twitter bots) as the latter post a much larger number of tweets than the former. Users with a high number of tweets from a same position were assessed on a case-by-case basis. Given the long tail distribution of the number of tweets per user, this was a small number. Those identified as bots were excluded from the database. Secondly, we needed users able to tweet from different positions in space, as they would provide more information for the trajectory analysis. We kept only users tweeting at least three times from different block sectors during the period. From the initial 20,192 users, this procedure led to 2,543 users, whose 20,029 tweets could generate spatial trajectories within the urban grid.

- Step 3 identified the probable residential location of users. Essentially, we needed to infer users' residential location in order to infer their probable trajectories. We did so assessing the repetition of position of the first tweet in the morning during the period of observation (i.e. first in a sequence of tweets). As the sample had been subject to previous filters, residential location could be inferred for all 2,543 users at this stage.

- Step 4 created shortest paths between tweet positions within Rio's street network, based on betweenness centrality, topological measure also developed by Freeman (1977). Considering the relation between tweet location and the actual street network, our study points to an accuracy within 10 meters, adjusted to the street network via shortest distance to the nearer street segment mapped in GIS software. The first tweets identified were taken as the origin of trajectories. Then we connected the positions of tweets sequentially posted during the period over Rio's street network. Shortest paths are largely used as predictors of actual routes (see Bovy, 2009; cf. Hillier et al, 1993). This topological operation was calculated using Dijkstra's (1959) algorithm and Open Street Maps (OSM).

- In step 5 Twitter users were differentiated according to income. We assigned income levels to users through a procedure that required crossing their residential locations with economic data collected in census blocks (2010 Census, Brazilian Institute of Geography and Statistics). In short, once we inferred residential location, we attributed the average income in the census block to users. The procedure of inferring individual users' income from the average of residents from each census block requires special attention, since there are risks of ecological fallacy involved. A sensitivity analysis about the heterogeneity of income within census blocks was required. We statistically assessed such risks looking for the coefficient of variation (CV) for income. Within the city of Rio de Janeiro, the census block unit has an average number of 210 households and 616 Inhabitants and a median area of 33,017 squared meters (a considerable variance is found for area). The average CV for income within census blocks in Rio is low, about $9.3 \%$, so there is enough homogeneity of income values between residents of a same census block to allow us to use average income as a proxy of individual income. The census block unit was the smallest available. Considering the goal in mind, other sources of information such as inferring income through text mining opened greater risks of interpretation.

- Finally, we analysed income distribution applying a standard classification for income in Brazil proposed by Neri (2010), based on consumption potential. This led to the following 
levels: less then $\mathrm{R} \$ 750 ; \mathrm{R} \$ 750.01$ to $\mathrm{R} \$ 1,600 ; \mathrm{R} \$ 1,600.01$ to $\mathrm{R} \$ 2,500 ; \mathrm{R} \$ 2,500.01$ to $\mathrm{R} \$ 3,400$; R\$ 3,400.01 per capita, and above. ${ }^{3}$ These values were identified as low, lower-middle, middle, upper-middle and high-income.

17 We also applied a methodological test to assess how representative is the inferred income of Twitter users' in relation to the actual population of Rio de Janeiro. Indeed data from actual incomes collected from the general population are contained in the income levels attributed to users through our procedure. However, the main risk at this stage was that Twitter users could have higher incomes and live in wealthier census blocks than the general population. That would imply a sample with a smaller proportion of lower income individuals, leading to an altogether different distribution of income, far from a reasonable picture of Rio's income scenario. So we compared the histogram of estimated income in our sample to the histogram of income found in Rio's population.

18 As expected, the histogram of population income (figure 2, bottom left) shows an exponential distribution with a long tail for higher income values (over R $\$ 10,000$ per month). The same threshold was observed for the estimated income distribution of Twitter users. Linear regression between the number of inhabitants and the number of twitter users for each neighbourhood brings an adjusted $R$ squared of 0.67 , showing that our sample of users has a reasonable degree of similarity with the spatial distribution of the population in general (figure 2, bottom right). This suggests that the use of Twitter is not associated with higher income levels, confirming previous findings about the high penetration rate of Twitter in Brazil (Graham and Stephens, 2012). The inferred distribution of users' residences along census blocks in Rio's territory reflects to a reasonable extent that of the general population, offering more reliability to our trajectory analysis. Figure 2 shows two readings: residential patterns of income levels (top) and the pattern of distribution of users' estimated location (below). 
Figure 2: Average income levels in census blocks (blue to red, on top), and estimated locations of Twitter users (centre). Below, histograms of average income per capita in Rio's population (left) and Twitter users (centre). Graph c (right) shows the regression between users $(Y)$ and population $(X)$ in census blocks. Colours of dots relate to average income.

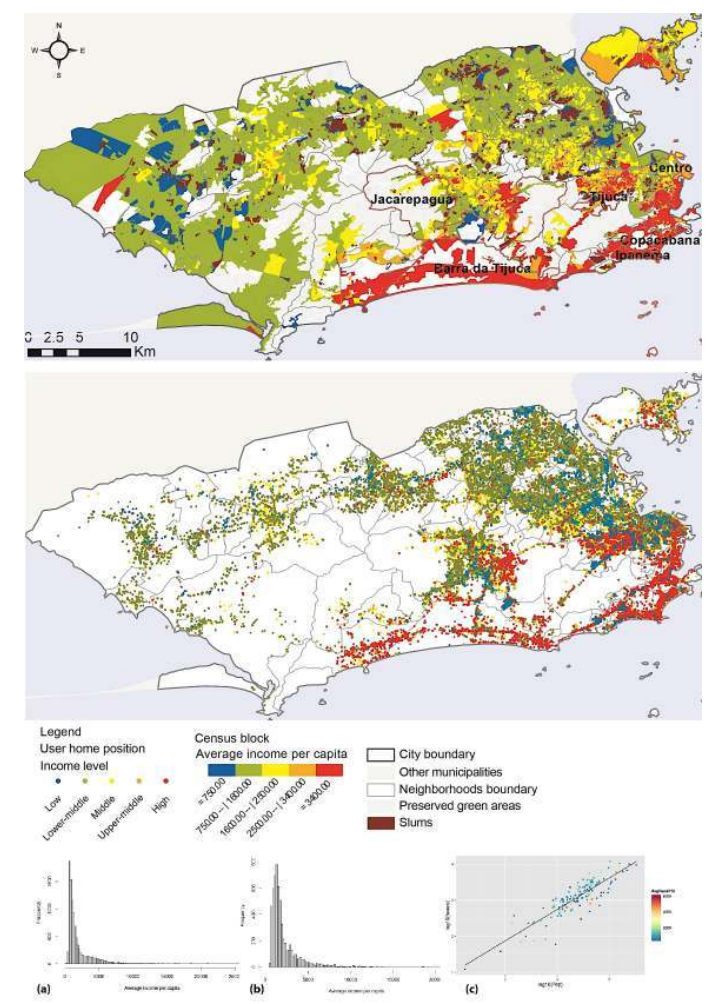

\section{Encounters in space and time: a digital experiment}

What does our experiment show about the dynamic of potential encounter between the socially different? We counted the number and extension of Twitter users' trajectories classified by income level for each street segment (between corners) where there were trajectories. This information was registered for each user and accumulated for her/his income group. Then we calculated the overlapping of trajectories of income groups, using the number of agents for each group passing through each street segment. Maps in figure 3 show the dominant income group in the streets that make up their trajectories. The criterion for determining visually the dominant presence of a single group over a street segment is 'the group with the higher number of paths overlapped in a street segment provides the colour for that segment' - i.e. once we consider the proportion of income groups in actual numbers, when a group has one or more persons above that percentage, it reaches dominant presence. 
Figure 3: A picture of segregated networks of movement: blue (low income), green (lower-middle), yellow (middle), orange (middle-upper) and red (high income) groups. The larger map shows the dominant class network.

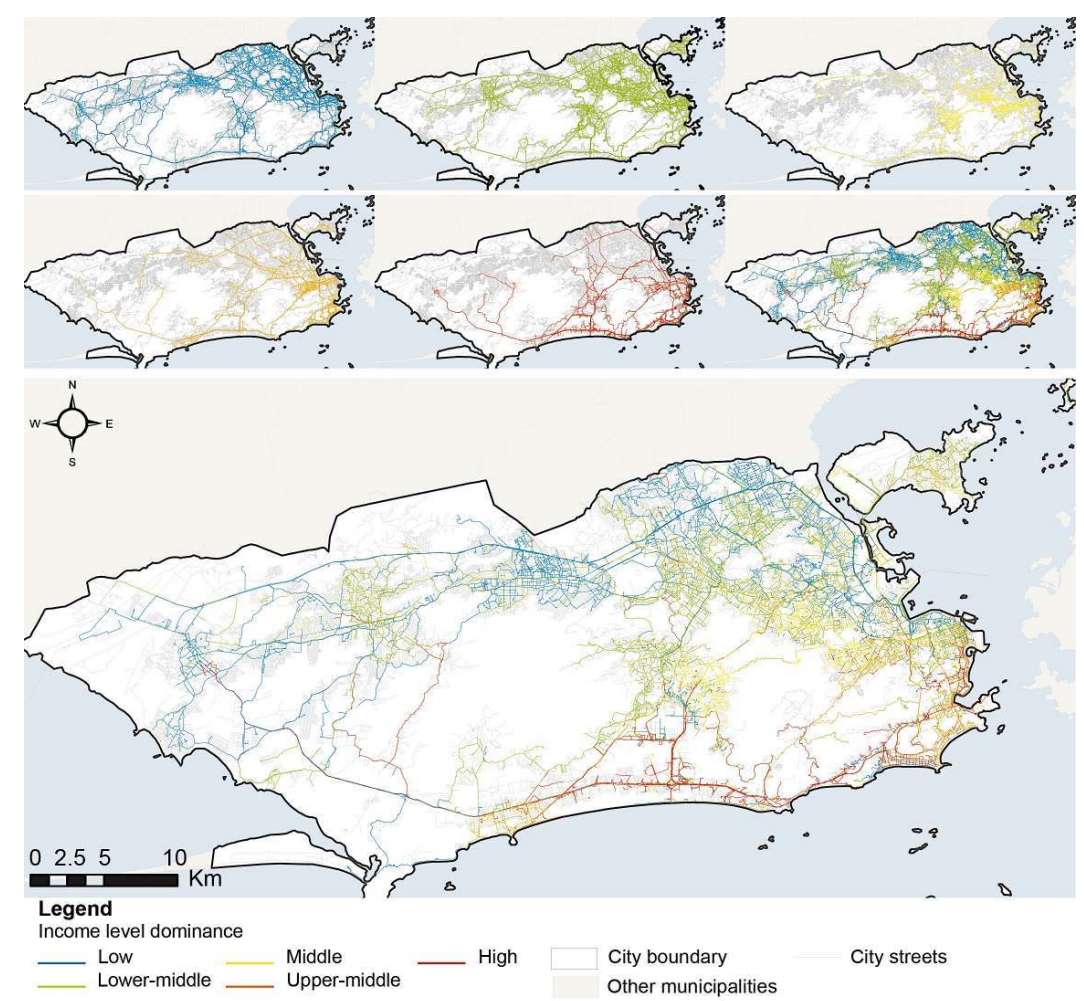

We first notice the strong influence of residential segregation related to income. The poorer are likely to live in north and west areas in Rio, farther from the Central Business district on the east, by the sea. Landscape amenities related to proximity to the sea are a clear factor in defining land values and higher income location in Rio. Geographical topography adds complexity to residential location patterns - including the favelas scattered in the landscape, allowing the poorer to live in hills near richer areas, closer to the sea and the CBD, to the East. Such unusual cityscape enmeshes trajectories, as we can see in areas in South Rio, increasing the potential of encountering the socially different. Second, results of the analysis show traces of a dynamic segregation. Trajectories of lower income users spread more broadly over the cityscape. Low-income and lower-middle income groups show considerable overlap, but low-income users are dominant in areas farther from the sea and the CBD, located in the East. Complexities considered, an overall pattern emerges, as higher income users are more likely to be found in South and Southeast Rio, near to the sea, and a gradual shift in users income levels becomes visible in trajectories as they spread farther, towards North.

21 Where are exactly the spaces that different social groups share? Poorer income groups (IG1xIG2) share much more spaces, mostly in North and West Rio (figure 4, left). In turn, the overlapping between the poorer and the richer (IG1XIG5) contains very few streets for mutual visibility between the socially different (figure 4, right). 
Figure 4: Overlapping lower-income (IG1xIG2) and high-income groups (IG1xIG5).

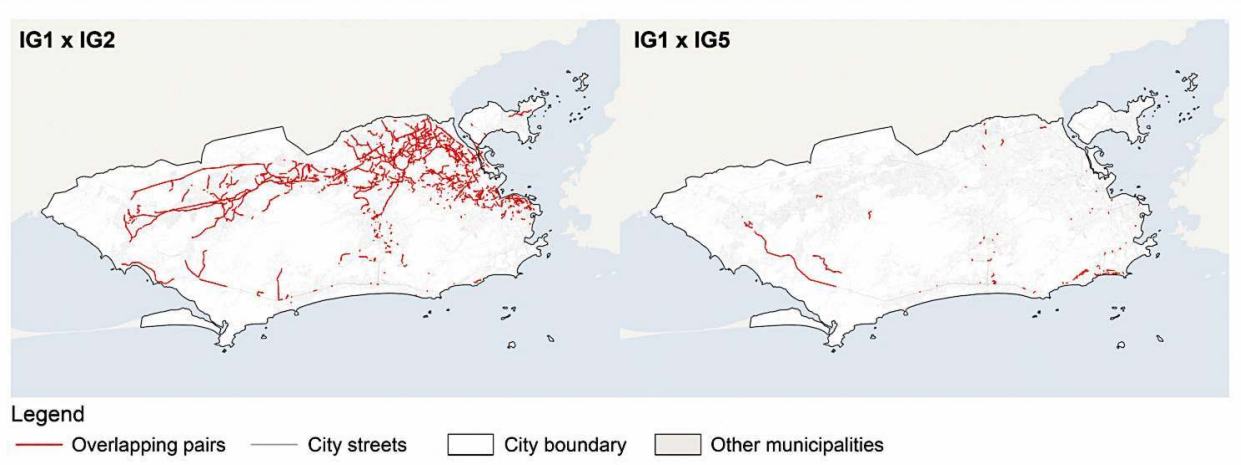

22 The visual overlapping of different income groups can also be assessed quantitatively, along with the isolated presence of a single group in Rio's streets, and the proportion of paths different income groups share with one another (table 1). Lower-income groups (IG1 and IG2) are much more segregated in their movements across the city, with 19.2\% and $29.9 \%$ of their trajectories occurring in non-shared streets, respectively. Their trajectories display less social diversity - they are easily the dominant group (i.e. their presence is above their proportional share in the total number of agents, all groups considered). They also show the highest degree of shared spaces between pairs of groups (10.4\%). IG2 displays a more socially integrative spatial behaviour - but also has a larger share of users (46.7\%). The fact that IG1 consists of $23.6 \%$ of total users and are dominant in $30.5 \%$ of streets where they pass through suggests they are more segregated than other groups in their movements. Finally, the poorer and the richer (IG1 and IG5) share only $0.8 \%$ of paths.

Table 1: Matrix of the proportion of streets (regarding the total number of streets) appropriated exclusively by a single income group (italic), and the proportion of streets shared by different income groups in their paths.

\begin{tabular}{|l|l|l|l|l|l|}
\hline & IG1 & IG2 & IG3 & IG4 & IG5 \\
\hline IG1 & $19.2 \%$ & $10.4 \%$ & $0.5 \%$ & $0.5 \%$ & $0.8 \%$ \\
\hline IG2 & & $29.9 \%$ & $1.5 \%$ & $1.7 \%$ & $1.2 \%$ \\
\hline IG3 & & & $4.3 \%$ & $0.2 \%$ & $0.3 \%$ \\
\hline IG4 & & & & $4.3 \%$ & $0.7 \%$ \\
\hline IG5 & & & & & $4.6 \%$ \\
\hline
\end{tabular}

Now considering the relationship between residential segregation and dynamic segregation, expressed in the trajectories of people in urban space, how much do different income groups actually pass through residentially segregated areas? We assessed this relationship crossing the average income in residential areas (census blocks) with the average income of the dominant group passing through those areas (table 2). However present in richer sectors, poorer groups (IG1 and IG2) strongly concentrate in poorer 
areas: $72.1 \%$ of IG1 trajectories happen in low-middle income sectors (S2). Richer users (IG4 and IG5) are the most likely to move within their own residential sectors (S5): $58.58 \%$ of IG5 trajectories happen in S5 areas. In turn, middle-income and middle-upper income sectors (S3 and S4) are open to more diverse income groups. The middle-income group (IG3) is the most distributed along different sectors in their movement across the city.

Table 2: Proportion of presence of income groups in residential sectors, considering local average income.

\begin{tabular}{|l|l|l|l|l|l|l|}
\hline \multirow{5}{*}{} & \multicolumn{5}{|l}{ Dominant presence of income groups (IG) } \\
\hline \multirow{5}{*}{ Residential Sectors } & & IG1 & IG2 & IG3 & IG4 & IG5 \\
\cline { 2 - 8 } & S1 & $9.1 \%$ & $3.9 \%$ & $3.6 \%$ & $1.7 \%$ & $5.2 \%$ \\
\cline { 2 - 8 } & S2 & $72.1 \%$ & $52.4 \%$ & $28.0 \%$ & $18.2 \%$ & $17.2 \%$ \\
\cline { 2 - 8 } & S4 & $2.0 \%$ & $30.1 \%$ & $29.3 \%$ & $15.9 \%$ & $7.4 \%$ \\
\cline { 2 - 8 } & S5 & $3.3 \%$ & $5.4 \%$ & $20.5 \%$ & $17.5 \%$ & $11.4 \%$ \\
\cline { 2 - 8 } & & $100 \%$ & $100 \%$ & $100 \%$ & $100 \%$ & $100 \%$ \\
\hline
\end{tabular}

So where do different income groups converge more intensely? What are the streets with more social diversity, where 'the other' is more likely to be seen? We measured social diversity on the streets, i.e. the level of superimposition of networks, through Shannon entropy (Shannon, 1948) calculated as the participation of each class over the total number of agents in each street segment. Spaces with the presence in equal shares of all income groups contain the highest diversity. Then we associated different diversity levels with colours from blue to red (figure 5). Diversity was calculated for every street segment. Intervals of proportion of income levels were statistically defined through natural breaks.

$$
\text { Diversity }=-\sum_{i} P_{i} \log _{2}\left(P_{i} / P t\right)
$$

where $P_{i}$ is the total number of users with income $i$ and $P_{t}$ the total number of users passing by each street segment 


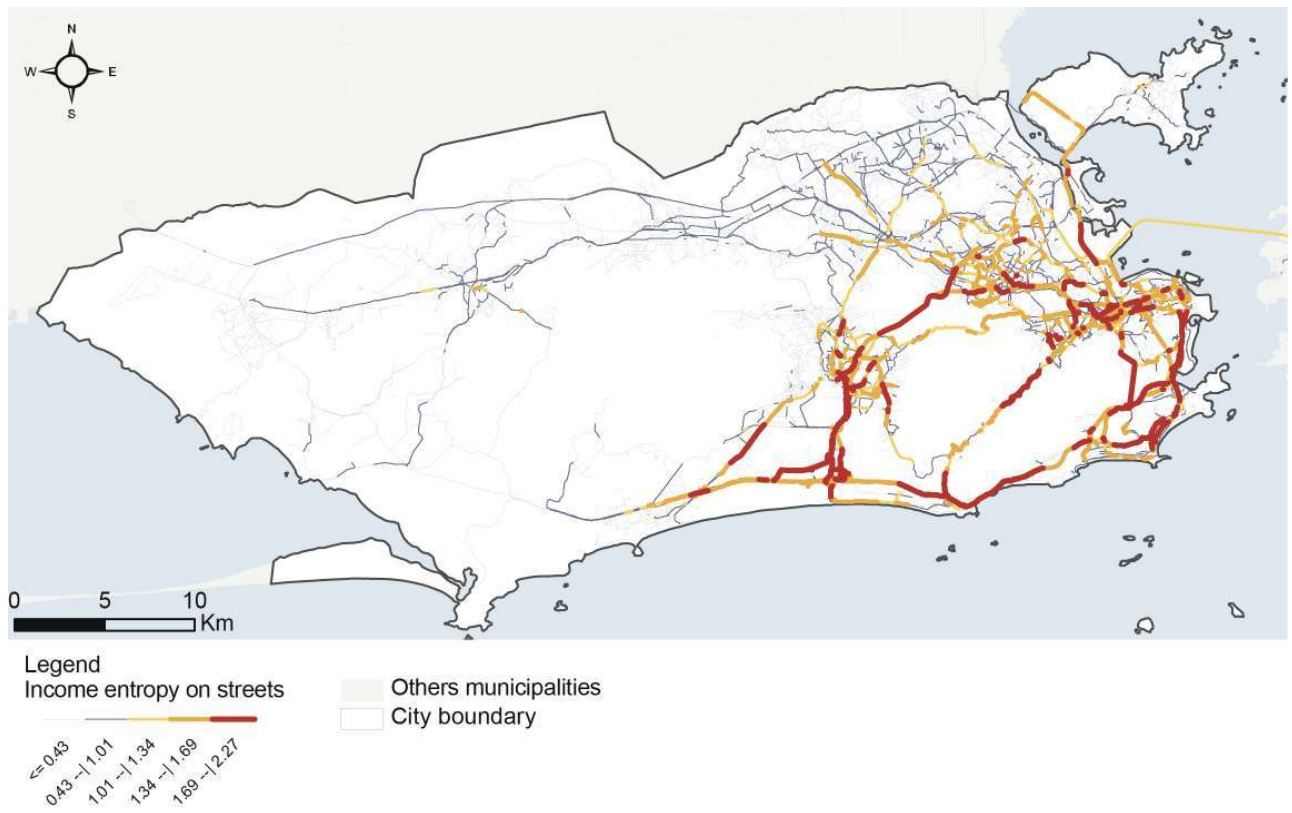

There is a small network of socially convergent streets, an interesting superimposition of trajectories of users of all income groups around South Rio (Copacabana and Ipanema) and the CBD (on the East). Spaces of social convergence are to be found in these denser, busier areas, and in major centralities like Tijuca and Jacarepaguá, a little to the North. These are the most likely spaces to find socially different agents.

We may further analyse the temporal structure of potential encounters between Twitter users. Using as databases the OSM network and the tweets dataset with timestamps and geolocation to rebuild the shortest paths between consecutive tweets, we also temporalized such trajectories assuming an average speed between tweet locations, given the timestamp of each tweet position.

Most importantly, we inferred 'potential encounter' as crossing trajectories within a single street segment and within a 'temporal window' of five minutes. We considered paths leading to tweeting positions. So even if users tweeted from inside a building, their paths were considered as the field of visibility. For simplicity, this field was defined as the street segment, close to the definition of isovists (Benedikt, 1979). Buildings contain barriers and partitions that do not allow fields of visibility as long as street segments as units of public space. In other words, we computed as potential encounter situations where two users were in a same street segment within a 5-minute interval. This temporal window of 5 minutes for potential encounters is of course an arbitrary definition able to encompass the amount of time a person may appear within the visual field of another while moving in a public space. It is broad enough to take into account the uncertainties inherent to the method regarding estimated trajectories and speed in movement.

Now we may assess the sequences of encounters in space-time through a time-geographyinspired representation and complementary graphic analyses (figure 6). Not surprisingly, the number of potential encounters peak in the early morning, around midday and around $5 \mathrm{pm}$ (see graph in figure 6, bottom left), and concentrate especially around the main channels of accessibility and Rio's CBD, to the East. Dots varying from blue to red indicate clusters of potential encounters (number of encounters is normalized between 0 
and 1 for positions of higher concentration). Potential encounters drop considerably in the evening, as agents tend to find themselves in more static positions in space. In order to understand the pattern of potential encounters, we applied Ripley's K-function to summarize spatial dependencies as clustering or dispersion processes over a range of distances randomly selected. As stated by Getis and Ord (2009), the K-function was calculated as:

$$
L(d)=\sqrt{\frac{A \sum_{i=1}^{n} \sum_{j=1 . j \neq 1}^{n} k_{i, j}}{\pi \times n(n-1)}}
$$

Where

$\mathrm{d}=$ distance between places of potencial encounter

$\mathrm{n}=$ total number of places of potencial encounter

$\mathrm{A}=$ total area comprehended by potencial encounters

$\mathrm{k}_{\mathrm{i}, \mathrm{j}}=$ weight (number of potencial encounters in each place).

The total number of estimated encounters between users in Rio is shown in the red line in the graph for the K-function (figure 6, bottom right). The blue line indicates the average distance between encounter places in randomly selected sets. The X-axis represents the distance between encounter places. The $\mathrm{Y}$-axis represents the average distance between encounter places weighted by the number of encounters. The difference between the lines indicates that observed encounters are clustered. As the curve for the observed $\mathrm{K}$ is above the confidence envelope, it is statistically significant.

Figure 6: Space-time prism for the varying intensity of potential encounters between Twitter users in Rio (top). Number of encounters in time (bottom left) and an analysis of their clusterization in space (K-Function, bottom right).
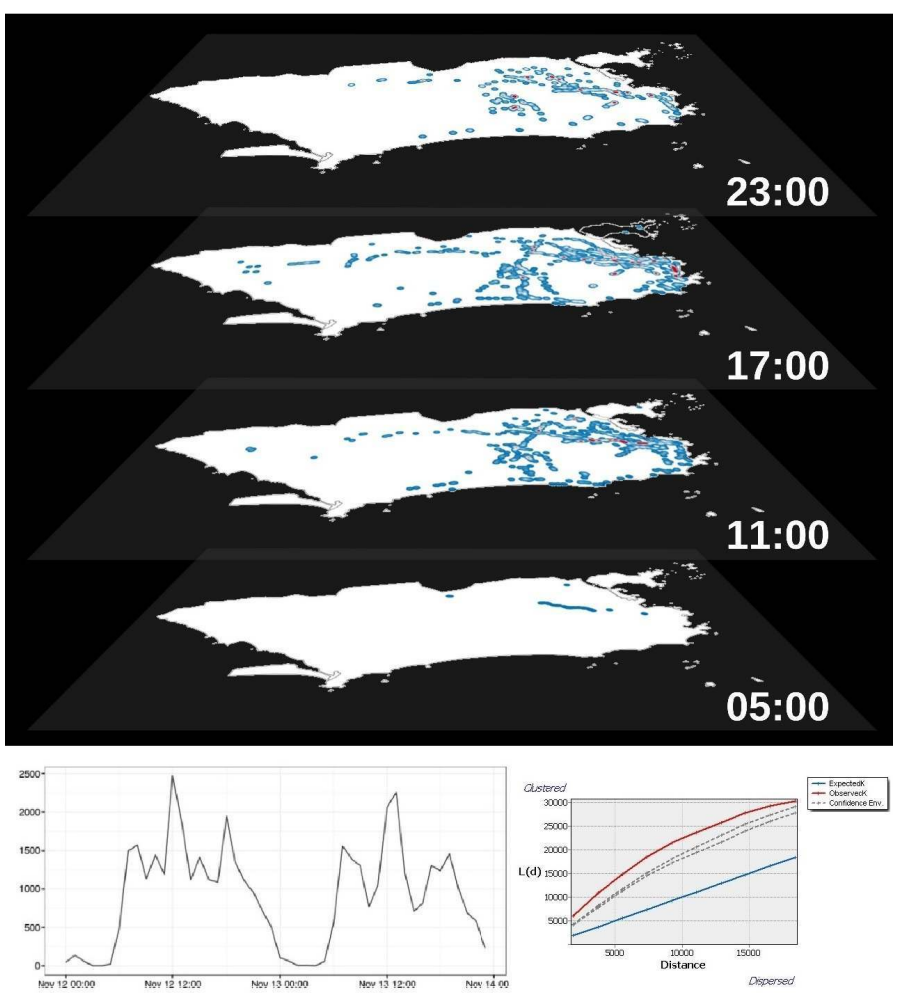
What does this pattern of overlapping imply in terms of potential encounters between users with different income levels? How can we assess precisely the effects of different income and spatiotemporal trajectories on encounter opportunities? In order to assess this, first we explored an income distribution with more levels (circles in grey tones in figure 7), and calculated the total number of potential encounters between groups of different income levels. Then we generated a more conventional social network analysis of agents grouped according to income. We used the ForceAtlas2 algorithm (Jacomy et al, 2014) to calculate relationships as a graph. The resulting graph is a proximity network relating income groups based on potential encounters. In this representation, vertices represent groups of users within a same income level. Links show the number of potential encounters between income groups. The higher the number of potential encounters, the shorter and thicker is the link. Figure 7 shows that poorer users are more likely to have contact; by the same token, higher income users are less likely to have contact with poorer users. Encounters are shown as simply more likely between socially similar people

Figure 7: Proximity network of users with different income levels.

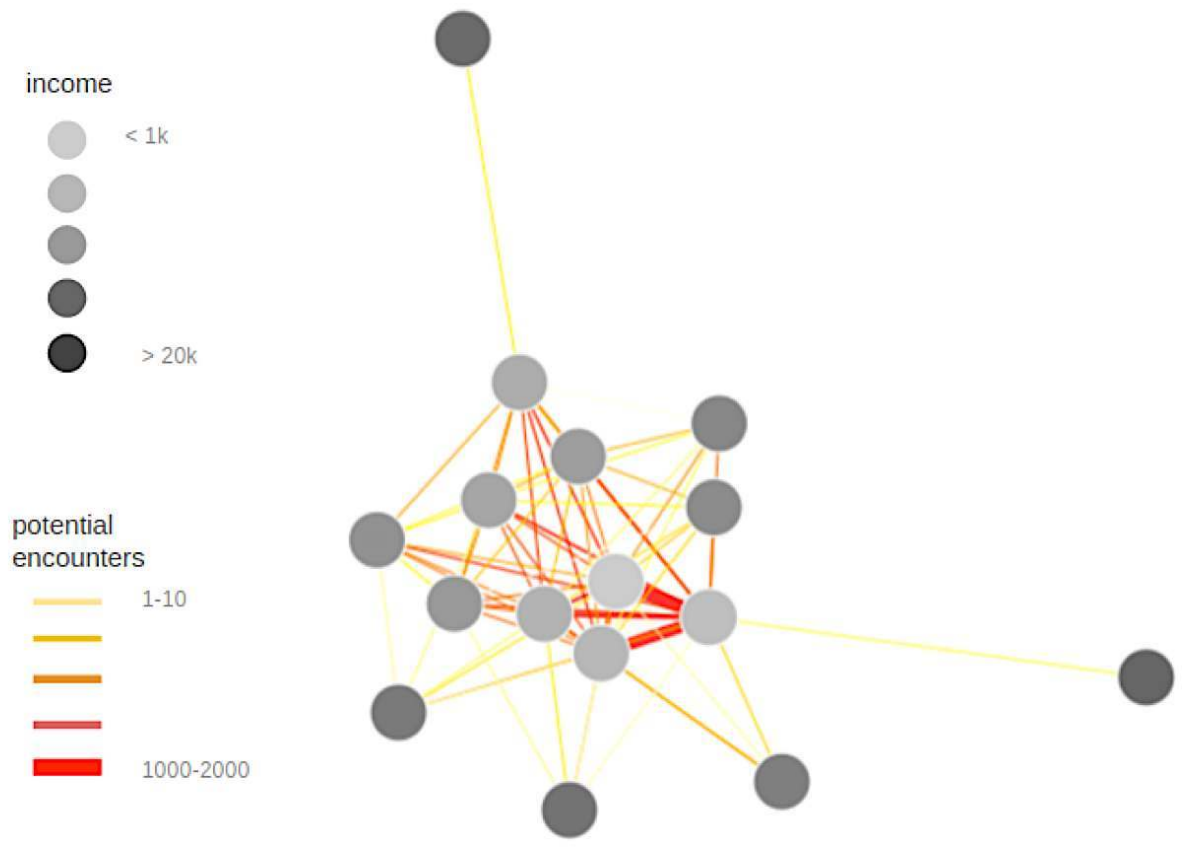

\section{Conclusion: space, time and segregation in the geography of encounter}

In this paper, we explored the role of urban trajectories in the creation of encounter opportunities - and its opposite, in the disjunction of encounters in a 'real time' form of segregation. We did so exploring the methodological use of social media locational data to grasp the trajectories of users and infer potential encounters between them. We applied this framework in an empirical study of trajectories and encounters of people with 
different income levels in Rio. We assessed levels of segregation and social diversity in the streets, and developed an analysis of proximity networks based on potential encounters.

Our approach is intended to shift the focus from social networks centred on agents to proximity networks generated by a 'temporal geography of encounters'. Our hypothesis was that the probability of encounters between large-scale groups includes but goes beyond residential location and spatial segregation. It would be shaped by income, by the distribution of activities, accessibility patterns, and by actual trajectories. Our look into spatiotemporal sequences of potential encounters allowed us to bring to the forefront a subtle face of segregation as a dynamic 'disjunction of encounters', close to Freeman's seminal definition of segregation as 'restrictions on contact'. In fact, the inferred paths of Twitter users show greater superimposition between socially similar users.

of course a number of questions can be posed: can poorly overlapping trajectories be interpreted as segregation? Is 'space sharing' enough to depict 'social integration'? Unlike most works, our approach is geared to trace the trajectories of people and relate them to patterns of social differentiation (in this case, based on income). It also suggests that different spatial trajectories lead to reduced opportunities for encounter, as seems to be the case between poorer and richer Twitter users. If Freeman (1978) is right in asserting that segregation operates through restrictions on contact, the lack of shared public spaces is an essential part of the experience of segregation.

Is a study based on Twitter data enough, however? However useful it could be, this experiment is not subject to control data, since that would require personal access to users in order to obtain information on real income levels and trajectories in the city, which cannot be carried on due to anonymity and research costs. Due to difficulties in generalising conclusions from samples of self-selecting users (Longley et al, 2015), procedures assigning location to users must be seen as a proxy rather than an actual scenario, as we insist. By the same token, assigning income levels of Twitter users from average income levels in census blocks requires caution. In Rio, income shows relatively low dispersion within census sectors, but this might be different elsewhere. Therefore, this step must be replicated with similar attention in other cases. As a proxy to the actual scenario of potential encounter and segregated networks, this experiment based on Twitter locational data can only show trends within the trajectories of a large number of people. As such, our study suggests that Twitter data is an invaluable means of identifying patterns of movement of people, with strong possibilities for understanding matters of social integration and equity.

Graphic and quantitative analyses of overlapping trajectories seem to add another layer to the understanding of segregation - beyond static maps of segregated activity or residential location. This is one of the aims of our approach: to get a look into segregated networks of movement along with the public spaces with potential for diversity, for the first time monitoring and measuring through locational data spatiotemporal differences in the appropriation of a city by members of different income groups. Neither segregated movement nor potentials for overlapping networks is inferable from income, activity or residential distribution maps alone.

Social media data are also a potential source for generating a precise temporal geography of encounters in a city, including the temporal dimension - a previously virtually impossible achievement. Our approach suggests that the probability of encounter is impregnated with spatiality, interacting actively with the street network to generate potentials of 
contact of social groups. The odds of finding 'the other' are distributed according to the spatial and temporal frames of action within a city.

\section{BIBLIOGRAPHY}

Batty M., 2013, The New Science of Cities. Cambridge, MA, The MIT Press.

Batty, M. (2017) “Endorsement”, Netto, V. M. The Social Fabric of Cities. London \& New York: Routledge.

Benedikt, M. L., 1979, “To take hold of space: isovists and isovist fields. Environment and Planning B, Vol. 6, 47-65.

Bettencourt L.M.A., 2013, “The origins of scaling in cities”, Science, Vol.340, 1348-1441.

Boettcher A. and Lee D., 2012, "EventRadar: A real-time local event detection scheme using Twitter stream", In Proceedings of the IEEE International Conference on Green Computing and Communications, Besançon, France, 358-67.

Bourdieu, P. 1985, “The Social space and the genesis of groups", Theory and Society Vol.14.6, 723744.

Bovy, P. H. L., 2009, “On modelling route choice sets in transportation networks: a synthesis”, Transport Reviews, 29:1, 43-68, DOI: 10.1080/01441640802078673

Dijkstra, E.W. (1959) "A note on two problems of connexion with graphs", Numerische Mathematik $1,269-271$

Fischer C., and Shavit Y., 1995, "National differences in network density: Israel and the United States", Social Networks, Vol.17.2, 129-45.

Freeman, L. (1977) “A set of measures of centrality based on betweenness", Sociometry 40, 35-41.

Freeman L., 1978, "Segregation in social networks", Sociological Methods and Research, Vol.6.4, 411429.

Getis, A., Ord, J. K., 1992, "The analysis of spatial association by use of distance statistics", Geographical Analysis, Vol.24, 189-206.

Giddens A., 1984, The Constitution of Society, Cambridge, Polity Press.

Goffman E., 1961, Encounters, Indianapolis, Bobbs-Merrill.

Gonzales M., Hidalgo C. and Barabási A-L., 2008, “Understanding individual human mobility patterns", Nature, Vol.453, 479-482.

Graham, M. and Stephens, M., 2012, “A Geography of Twitter”, WWW document, http:// www.oii.ox.ac.uk/vis/?id=4fe09570.

Hägerstrand T., 1970, "What about people in regional science?", Papers of the Regional Science Association, Vol.24.1, 6-21.

Hillier B., Hanson J., 1984, The Social Logic of Space, Cambridge, University Press. 
Hillier B., Penn A., Hanson J., Grajewski T. and Xu J., 1993, "Natural movement: or, configuration and attraction in urban pedestrian movement", Environment and Planning B: Planning and Design Vol.20, No.29, 29-66.

Hillier, B., Vaughan, L., 2007, “The city as one thing”, Progress in Planning , Vol.67, No. 3, 205-230, doi 10.1016/j.progress.2007.03.001

Hunt, C. L. e Walker, L. (1974) Ethnic dynamics: patterns of inter-group relations in various societies. Homewood, IL: Dorsey.

Jacomy, M., Venturini, T., Heymann, S. and Bastian, M., 2014, "ForceAtlas2, a Continuous Graph Layout Algorithm for Handy Network Visualization Designed for the Gephi Software", PLoS ONE Vol.9, No.6, e98679, doi:10.1371/journal.pone.0098679.

Kwan, M-P., 2013, “Beyond Space (As We Knew It): Toward Temporally Integrated Geographies of Segregation, Health, and Accessibility”, Annals of the Association of American Geographers, Vol. 103 (5) DOI: 10.1080/00045608.2013.792177

Lee K.H., Lippman A. and Pentland A., 2011, “The Impacts of Just-In-Time Social Networks on People's Choices in the Real World", The Third International Conference on Social Computing.

Lee R., Ruan D. and Lai G., 2005, “Social structure and support networks in Beijing and Hong Kong”, Social Networks, Vol.27.3, 249-74.

Lee J. and Kwan M-P., 2011, "Visualisation of socio-spatial isolation based on human activity patterns and social networks in space-time", Tijdschrift voor Economische en Sociale Geografie, Vol.102.4, 468-485.

Li W., Serdyukov P., Vries A.P., Eickhoff C., and Larson M., 2011, “The where in the tweet”, In Proceedings of the Twentieth ACM International Conference on Information and Knowledge Management, Glasgow, Scotland.

Longley P.A., Adnan M. and Lansley G., 2015, “The geotemporal demographics of Twitter usage”, Environment and Planning A, Vol.47, No.2, 465-484.

Marques E.C., 2012, "Social Networks, Segregation and Poverty in São Paulo", International Journal of Urban and Regional Research, Vol.36, Nr.6, 958-979.

Netto, V.M., Krafta, R., 1999, “Segregação dinâmica urbana: modelagem e mensuração.” Revista Brasileira de Estudos Urbanos e Regionais, v.1, p.133-152.

Netto, V.M., Krafta, R. 2001 "Socio-spatial networks: social segregation as a real-time phenomenon", In: Proceedings of the 3rd International Space Syntax Symposium. Atlanta, GeorgiaTech Netto, V.M., Pinheiro, M., Paschoalino, R., 2015, “Segregated networks in the city”, International Journal of Urban and Regional Research 39 (6) 1084-1102.

Netto, V.M., 2017, The Social Fabric of Cities. London \& New York: Routledge.

Neri, M. C., 2010, A nova classe média: o lado brilhante dos pobres. Rio de Janeiro: FGV.

Park, Y.M., Kwan, M-P., 2017, “Multi-Contextual Segregation and Environmental Justice Research: Toward Fine-Scale Spatiotemporal Approaches", International Journal of Environmental Research and Public Health, Vol.14, 1205, doi:10.3390/ijerph14101205

Ribeiro S., Davis C., Oliveira D., Meira W., Gonçalves T., and Pappa G., 2012, “Traffic Observatory: A system to detect and locate traffic events and conditions using Twitter", In Proceedings of the Fifth International Workshop on Location-Based Social Networks, Redondo Beach, California, 5-11. 
Sakaki T., Okazaki M., and Matsuo Y., 2010, "Earthquake shakes Twitter users: real-time event detection by social sensors", In Proceedings of the Nineteenth International Conference on the World Wide Web, Raleigh, North Carolina, 851-60.

Schnell I., and Yoav B., 2001, "The Socio-Spatial Isolation of Agents in Everyday Life Spaces as an Aspect of Segregation”, Annals of the Association of American Geographers, Vol.91, No.4, 622-633.

Schnell I., and Yoav B., 2005, "Globalisation and the Structure of Urban Social Space: The Lesson from Tel Aviv”, Urban Studies, Vol. 42, No. 13, 2489-2510.

Shannon, C. E., 1948, "A mathematical theory of communication", Bell System Technical Journal, jul./out.

Selim G., 2015, “The landscape of differences: contact and segregation in the everyday encounters", Cities, Vol.46, 16-25.

Takhteyev Y., Gruzd A., and Wellman B., 2012, "Geography of Twitter networks", Social Networks Vol.34, 73-81.

Veloso A. and Ferraz F., 2011, "Dengue surveillance based on a computational model of spatiotemporal locality of Twitter", In Proceedings of the Third International Conference on Web Science, Koblenz, Germany.

Wasserman S. and Faust K., 1994, Social Network Analysis: Methods and Applications, Cambridge, University Press.

Wissink, B., Schwanenb, T., and Van Kempen, R., 2016, "Beyond residential segregation: Introduction", Cities, Vol. 59, 126-130.

Zielinski A. and Middleton S., 2013, "Social media text mining and network analysis for decision support in natural crisis management", In Proceedings of the Tenth International Conference on Information Systems for Crisis Response and Management, Baden-Baden, Germany.

\section{NOTES}

1. See classic graph theoretical approaches in Freeman (1978) and Wasserman and Faust (1994), among others.

2. Empirical data on transport expenses in Brazil show that higher income groups not only spend more than low-income groups, they do so more than proportionally (POF, 2009).

3. The exchange rate between American Dollars and the Brazilian currency Reais is: U\$ $1=\mathrm{R} \$$ 3.30 in $30^{\text {th }}$ September, 2016.

\section{ABSTRACTS}

Integrating social and spatial networks will be critical to new approaches to cities as systems of interaction. In this paper, we focus on the spatial and temporal conditions of encounters as a key condition for the formation of social networks. Drawing on classic approaches such as Freeman's concept of segregation as 'restriction on contact', Hägerstrand's time-geography, and recent 
explorations of social media locational data, we analysed the space-time structure of potential encounters latent in the urban trajectories of people with different income levels in Rio de Janeiro, Brazil. This approach allows us to estimate trajectories examining spatiotemporal positions in tweets, and assess spaces of potential encounter and levels of social diversity on the streets. Finally, we discuss the utility and limitations of an approach developed to grasp how clusters of encounters between groups with different income levels are produced.

Intégrer les réseaux sociaux et spatiaux s'avérera critique dans les nouvelles approches des villes comme systèmes d'interactions. Dans cet article, nous nous concentrons sur les conditions spatiales et temporelles des rencontres comme l'élément clé pour la constitution de réseaux sociaux. En se basant sur les approches classiques telles que le concept de ségrégation comme "restriction on contact» de Freeman, la géographie-temps de Hägerstrand et les récentes explorations de données locales des médias sociaux, nous analysons la structure espace-temps des rencontres potentielles, latentes dans les trajectoires urbaines des personnes à différents revenus, à Rio de Janeiro, Brésil. Cette approche nous permet d'estimer les trajectoires en examinant les positions spatiotemporelles dans les tweets et d'évaluer les espaces potentiels de rencontres et les niveaux de diversité sociale dans les rues. Enfin, nous discutons de l'utilité et des limites d'une approche qui vise à saisir comment les groupements de rencontres entre différents groupes de revenus différents sont générés.

INDEX

Keywords: social network, encounter, segregation, Twitter, spatial data

Mots-clés: réseau social, rencontre, ségrégation, twitter, données spatiales

geographyun 904, 931, 76

\section{AUTHORS}

\section{VINICIUS M. NETTO}

Universidade Federal Fluminense, UFF, Rio de Janeiro state, Brazil vmnetto@id.uff.br |

www.socialfabric.city

\section{JOÃO VITOR MEIRELLES}

Laboratory on Human-Environment Relations in Urban Systems HERUS, EPFL, Switzerland

joao.meirelles@epfl.ch

\section{MAÍRA PINHEIRO}

Escola Nacional de Ciência Estatística, IBGE, Brazil mairasoares.arq@gmail.com

\section{HENRIQUE LOREA}

Universidade Federal do Rio Grande do Sul, UFGRS, Brazil henriquelorealeite@gmail.com 